\section{Singularidade e Universalidade nos processos de leitura de Kierkegaard}

\author{
José Miranda Justo \\ Centro de Filosofia da Universidade \\ de Lisboa, Faculdade de Letras da \\ Universidade de Lisboa
}

Resumo: Com muita frequência encontramos comentadores da obra de Søren Kierkegaard que procuram ultrapassar a diversidade e a heterogeneidade interna da produção kierkegaardiana mediante processos de redução à unidade, em particular transformando o filósofo dinamarquês exclusivamente num pensador religioso. A título de exemplo, o presente artigo começa por abordar a leitura que Jean Starobinski oferece desse tipo de redução. Subsequentemente o artigo procura caracterizar em pormenor a diversidade e a heterogeneidade kierkegaardianas e encontrar para elas um tipo de resposta baseado em pressupostos de natureza hermenêutica, designadamente numa teoria da singularidade e da universalidade da experiência que consiga ultrapassar os extremos de uma dicotomia radical entre unidade a todo o custo e multiplicidade inoperante. A última parte deste trabalho trata de exemplificar a aplicabilidade dos conceitos de singularidade e de universalidade numa sequência de casos concretos da produção de Kierkegaard, concluindo pela integração de tais conceitos numa compreensão da construção da subjectividade existencial do leitor dessa produção.

Palavras chave: Kierkegaard, Starobinski, unidade, singularidade, universalidade, subjectividade

\author{
Singularity and Universality in \\ reading processes Kierkegaard
}

Abstract: It is common to find commentators of Kierkegaard's oeuvre who try to overcome the diversity and heterogeneity inherent to the Danish philosopher's production by applying procedures of reduction to unity, in particular by transforming Kierkegaard into an exclusively religious thinker. The example provided in the beginning of the present paper examines Jean Starobinski's reading of the philosopher according to such a problematic approach. Subsequently the paper characterizes in detail the diversity and heterogeneity in Kierkegaard's writing in order to provide an answer for this diversity and heterogeneity based on hermeneutic presuppositions, by putting forward a theory of the singularity and the universality of experience which might surpass the polarities drawn by a radical dichotomy between unity at all cost, on one side, and inoperative multiplicity, on the other. The last section of this paper exemplifies the applicability of the concepts of singularity and universality by means of a sequence of situations taken from Kierkegaard's production. The conclusion re-instates the integration of both concepts within an understanding of the construction of the reader's existential subjectivity.

Key words: Kierkegaard, Starobinski, unity, singularity, universality, subjectivity 
Singularidade e Universalidade nos processos de leitura de Kierkegaard

Ninguém sabe quem foi verdadeiramente Kierkegaard, nem o que quis dizer.

Karl Jaspers (1970: 63) $)^{1}$

Sendo o tema geral desta 41. Semana de Filosofia da Universidade de Brasília "O debate acerca da subjectividade nos 200 do nascimento de Kierkegaard", entendi ser apropriado falar, não tanto da temática da subjectividade dentro da obra de Kierkegaard, mas mais especificamente do papel do sujeito - e, portanto, da subjectividade do sujeito, se me é permitida esta expressão aparentemente pleonástica - na leitura de Kierkegaard e na recepção que hoje podemos fazer da sua $\mathrm{obra}^{2}$. Porque, se é verdade que há todo um debate em curso em torno do tema da subjectividade em Kierkegaard, creio que há igualmente um debate a fazer sobre o modo como as subjectividades (a subjectividade de cada um) podem lidar com a obra (ou segmentos da obra) de Kierkegaard.
Os leitores da imensa bibliografia existente sobre Kierkegaard e os seus pseudónimos estão familiarizados com as inúmeras tentativas de reduzir a multiplicidade de autores, estilos e tópicos da produção do filósofo dinamarquês a um qualquer tipo de unidade. A redução à unidade parece ser muitas vezes uma espécie de prioridade, ou então um objectivo último, como se não fosse possível uma discursividade hermenêutica em torno de Kierkegaard sem ter, pelo menos no horizonte da interpretação ou da leitura, um propósito de unificação de tudo aquilo que nos surge necessariamente sob o signo da diversidade. Aliás, como é sabido, o próprio Kierkegaard, com um texto particularmente controverso publicado postumamente em 1859, O Ponto de Vista Face à Minha Actividade de Autor, contribuiu seriamente para algumas das versões daquilo a que chamarei redução à unidade. Mas não irei deter-me em particular nesse facto $^{3}$.

Naquilo que vos vou apresentar, começarei por observar os argumentos de um respeitado comentador que se move na direcção dessa redução à unidade: Jean Starobinski. A segunda parte da minha comunicação tratará do problema da diversidade e da heterogeneidade em Kierkegaard, por oposição às tentativas de redução à unidade. Finalmente, na terceira parte introduzirei um conceito de singularidade - articulado como uma certa concepção de universalidade - que

\footnotetext{
${ }^{1}$ No momento em que redijo esta minha conferência de encerramento da " $41^{\text {a }}$ Semana de Filosofia da UnB" tenho à minha disposição apenas a versão espanhola que consta das referências bibliográficas.

$2 \mathrm{O}$ texto deste meu trabalho retoma no essencial as linhas gerais da argumentação que desenvolvi recentemente num artigo entretanto publicado num número especial da Rivista di Filosofia Neoscolastica, de Milão, dedicado a Kierkegaard (JUSTO, 2013b).

${ }^{3} \mathrm{Vd}$. adiante nota 7 .
}

Revista de Filosofia Moderna e Contemporânea

Brasília, vol 2, n 1, 2014. 
procurará encontrar vias para lidar com a pluralidade de problemas no nosso autor, sem recorrer a processos de uma unificação que considero ser artificial.

\section{Um exemplo de redução à unidade em Jean Starobinski}

Num magnífico volume publicado há precisamente um ano, com o título de L'Encre de la mélancolie, Jean Starobinski (2012) ${ }^{4}$ reúne vários ensaios de diferentes épocas da sua produção. Três dos ensaios debruçam-se sobre Kierkegaard. São textos que originariamente foram publicados nos anos sessenta do século passado ${ }^{5}$ e que parecem ter sido entretanto praticamente esquecidos pelos estudos kierkegaardianos, o que torna a sua nova publicação tanto mais digna de nota. O primeiro ensaio só em parte se reporta a Kierkegaard. Concentrar-me-ei no segundo ensaio, no qual os argumentos que me interessam para os objectivos aqui em vista se encontram também mais desenvolvidos do que no terceiro.

Nesse segundo ensaio, Starobinski começa com o tópico da máscara na compreensão kierkegaardiana da existência e desenvolve a ideia de que por trás da máscara tem de haver um rosto que corresponde também a um "verdadeiro nome" ou "verdadeiro eu" (no sentido do francês "un vrai moi", ou seja algo que poderíamos também traduzir pelos substantivos self em inglês, Selbst em alemão ou selvet em dinamarquês, mas que o português eu dificilmente pode traduzir com rigor). Cito a última parte da sequência argumentativa de Starobinski:

Viver em estado de sombra, viver entre parênteses, ser o duplo de um outro, tal é o tormento daquele que abandonou o seu verdadeiro en [vrai moi] on que foi abandonado por ele. Só que é preciso supor que um verdadeiro eu existe, que uma edição original foi registada antes de todas as contrafacções. Há portanto um rosto, um nome, uma essência, que são nossos, desde toda a eternidade. [...] Para validar este verdadeiro nome, para lhe conferir a existência é necessário aceitar a intervenção de uma $V o z$. transcendente. [...] O meu "verdadeiro" nome [...] é aquele pelo qual Deus me chama. (STAROBINSKI, 2012: 387)

Estamos aqui confrontados com a prévia existência "essencial" de um "verdadeiro eu". Este "eu" é depois perdido, mas pode ser novamente alcançado, pode ser recuperado. E é recuperado precisamente quando a sua existência é garantida por intermédio de um certo chamamento de Deus, um chamamento pelo "verdadeiro nome" do sujeito desse eu. Sucede, porém, que este conglomerado é imediatamente posto em relação com a pseudonímia kierkegaardiana. Escreve Starobinski:

A pseudonimia [...] pode simbolizar a distância que nos separa de um nome autêntico que aspiramos a assumir, e fora do qual estamos ainda exilados. Num primeiro nivel, no estádio estético, a pseudonímia representava a fuga e a recusa do nome contingente de que não queríamos ser prisioneiros; no segundo

\footnotetext{
${ }^{4}$ No seguimento, a tradução de passagens desta obra para português é da minha responsabilidade.

5 "La princesse Branbilla" (STAROBINSKI, 2012: 361-384), "Kierkegaard, les pseudonymes du croyant" (STAROBINSKI, 2012, pp. 385-401), "Repentir et intériorité" (STAROBINSKI, 2012: 403-417). Estes textos foram originariamente publicados nos seguintes periódicos: Critique, $\mathrm{n}^{\circ}$ 228, 1966, Revue de théologie et de philosophie, IV, 1963, e Nouvelle Revue française, $\mathrm{n}^{\circ}$ 148, 1965.
}

Revista de Filosofia Moderna e Contemporânea

Brasília, vol 2, n 1, 2014. 
Singularidade e Universalidade nos processos de leitura de Kierkegaard

nivel, pelo contrário, no estádio ético, a pseudonimia traduz o sentimento de não se ter ainda conquistado o direito de cidadania interior e de se estar distante do objectivo, no esforço de integração ou de reintegração do nome autêntico. (STAROBINSKI, 2012: 387-388)

Tal significa que os escritos pseudonímicos de Kierkegaard deveriam ser vistos como parte de uma trajectória que conduz de um momento em que o "eu" já foi perdido e o "nome contingente" é recusado (embora não possa ser realmente substituído) até um momento posterior em que irrompe a consciência da enorme distância que dista até ao "nome autêntico" e à recuperação do "eu". Parece portanto claro que esta recuperação do "eu" - ou pelo menos uma visão distante do que ela possa ser ocorrerá mais tarde, quando for alcançado o estádio religioso. Contudo, o que pretendo sublinhar neste momento é o facto de esta perspectiva unificar totalmente o território da pseudonímia ao atribuir aos estádios estético e ético localizações fixas dentro da trajectória, a qual, por seu turno, é estabelecida independentemente da pseudonímia, sendo inclusivamente prévia em relação a ela. De acordo com esta perspectiva, a multiplicidade dos autores kierkegaardianos não pode de facto ser avaliada em si mesma, já que, desde o princípio, se encontra reduzida à função unificadora do esquema: eu - euperdido - eu-recuperado; ou, por outras palavras: nome verdadeiro - nome contingente - nome verdadeiro.

O modo como Starobinski prossegue o seu ensaio apenas confirma esta descrição:
A busca de si desemboca [...] num face-a-face com a transcendência divina, fundamento impenetrável da existência singular. É de Deus, visado como face invisivel, que o homem recebe a sua face visivel. Dai em diante, o nome que deve assumir, mas que lhe é dado - o nome que é a plenitude pessoal, o nome ao mesmo tempo limitado e infinito que o homem nunca chega a incarnar completamente -, aparecerá como o mandatário simbólico da transcendência. Kierkegaard tem o sentimento de que o seu verdadeiro nome o espera para lá do instante presente, por trás do mundo dos pseudónimos. (STAROBINSKI, 2012: 389)

Neste contexto, o "mundo dos pseudónimos" parece não ser de facto outra coisa senão $o$ estado transitório necessário para entrever a região transcendente em que o "verdadeiro nome" aguarda por aquele que o perdeu e que entretanto ganhou consciência dessa perda e da necessidade de o recuperar. $\mathrm{O}$ facto de Starobinski admitir que "o homem nunca chega a incarnar completamente" esse "verdadeiro nome" que é a sua "plenitude pessoal" não chega a alterar o carácter redutivo da argumentação. Em termos teóricos, a trajectória esquemática que mencionámos continua a ser a mesma, mesmo se se acrescenta que ela não pode ser totalmente completada em termos objectivos. Sendo assim, o efeito de redução à unidade permanece intocado.

Mas há mais. Quando Starobinski penetra mais profundamente no processo pseudonímico de Kierkegaard e na respectiva relação com os textos religiosos publicados sob o nome do autor, cita $O$ Ponto de Vista Face à Minha Actividade de 
Autor ${ }^{6}$, e prossegue com o seguinte comentário:

\begin{abstract}
Kierkegaard reconbece que a estética fazia parte integrante da sua vida; mas, uma vez que se libertou dela, ela toma aos seus olhos um outro sentido, e declara que ela foi sempre uma máscara pedagógica. Se a sucessão dos pseudónimos designa um imperativo de transformação interior, Kierkegaard assegura que a transformação se manifestou desde o primeiro momento, ao mesmo tempo na sua urgência e no seu acabamento. Kierkegaard não quer passar por um esteta arrependido $e$ progressivamente conquistado para a fé religiosa. (STAROBINSKI, 2012: 392)
\end{abstract}

O facto de a transformação do estético no religioso se manifestar desde o início no seu acabamento (ou completude) coloca-nos perante um problema delicado. A transformação encontra-se - ou devia encontrar-se - numa relação de analogia (se não de homologia) com a sequência eu - eu-perdido - eu-recuperado que detectámos acima, já que a transformação agora invocada por Starobinski é precisamente aquela que está em jogo na pseudonímia, como se dizia atrás, ou na "sucessão dos pseudónimos", como se diz agora. Porém, quando se entende que a estética "foi sempre uma máscara pedagógica", a própria sucessão dos pseudónimos, enquanto imperativo de transformação, parece estar posta em causa. Pode perguntar-se se subsiste algum espaço para qualquer tipo de sucessão dos pseudónimos, se, de facto, o estético e o religioso são entendidos como totalmente paralelos e como tendo iniciado as respectivas funções e presença "desde o primeiro momento", ou seja, desde um mesmo e único início. Deste ponto de vista, o eu-perdido, que deveria ser característico do estético e que deveria ser (parcialmente) recuperado no plano do religioso, parece não ter sido perdido nem ser recuperado em nenhum momento possível.

Da perspectiva em que me coloco, o problema que acabamos de detectar não decorre tanto das declarações de Kierkegaard em O Ponto de Vista Face à Minha Actividade de Autor, que são contraditórias com outras que conhecemos, por exemplo, de "Uma primeira e última

\footnotetext{
${ }^{6}$ As duas passagens citadas por Starobinski (2012: 391-392), com base no vol. XVI das CEuvres Complètes, são as seguintes (transcrevo o original dinamarquês e traduzo). Primeira passagem: "Og Eet maa da Forfatteren ikke glemme, Menten, hvilket der er hvilket, det Religieuse det Afgjørende, det Æsthetiske Incognito'et, at ikke den dialektiske Krydsen ender med at slaae Sladder." (SKS 16, 34) "E uma coisa o autor tem de não esquecer, o número a adicionar na coluna seguinte, qual é qual, o religioso o decisivo, o estético o incógnito, a não ser que a intersecção dialéctica acabe em tagarelice vazia." Starobinski cita apenas: "le religieux est le décisif, tandis que l'esthétique est l'incognito". Segunda passagem : "Processen er: en digterisk og philosophisk Natur skaffes tilside for at blive Christen. Men det Usædvanlige er, at Bevægelsen begynder samtidigt, og derfor er det en bevidst Proces; man faaer at see, hvorledes det gaaer til; det Andet indtræder ikke ved en Række Aars Adskillelse fra det Første. Saaledes er vistnok den æsthetiske Produktivitet et Bedrag, dog $\mathrm{i}$ en anden Forstand en nødvendig Udtømmelse." (SKS 16, 57) "O processo é [o seguinte]: uma natureza poética e filosófica é afastada para o lado para se tornar um cristão. Mas o inusitado é que o movimento começa ao mesmo tempo, e por isso trata-se de um processo consciente; consegue ver-se como acontece; o segundo não começa com uma separação de anos do primeiro. Assim, decerto a produtividade estética é um engano, contudo num outro sentido é uma evacuação necessária."
} 
Singularidade e Universalidade nos processos de leitura de Kierkegaard

explicação" ou de entradas dos Diários ${ }^{7}$, mas sobretudo do tipo de redução à unidade posto em prática por Starobinski. $\mathrm{O}$ facto de ser invocado um "verdadeiro eu" (ou um "nome verdadeiro") e de isso ser feito numa perspectiva essencialista, segundo a qual "há $[\ldots]$ um rosto, um nome, uma essência que são nossos, desde toda a eternidade", é responsável pela redução total dos processos subsequentes à unidade dessa "essência". Tal significa que toda a pluralidade de perspectivas ou de actividades - incluindo as actividades de escrita dos pseudónimos e do autor que usa o nome de Kierkegaard desde os Discursos Edificantes até O Ponto de Vistaserá sempre visto como estando numa fundamental dependência em relação a essa "essência" que é o "verdadeiro eu", que afinal governa todo o processo, e que na verdade só aparentemente se encontra perdida durante um certo período de tempo. A sequência eu-verdadeiro - euperdido - eu-recuperado e a ideia de que "a transformação [do estético no religioso] se manifestou desde o primeiro momento, ao mesmo tempo na sua urgência $e$ no sen acabamento" não são na verdade contraditórias. Limitam-se a dar corpo, de duas maneiras divergentes, à mesma perspectiva reducionista de acordo com a qual existe sempre um factor antes e por trás de todos os outros factores, um factor que domina e submete a uma unidade previamente estabelecida toda a diversidade possível que podemos detectar ao longo do processo de relacionamento com o eu, ou ao longo dos diferentes processos em jogo na produção de Kierkegaard.
Veremos agora como uma tal perspectiva reducionista pode ser contraditada por factores como a diversidade e a heterogeneidade, os quais na verdade desempenham um papel constitutivo na obra de Kierkegaard.

\section{Diversidade e heterogeneidade em Kierkegaard}

Em ocasiões anteriores tive oportunidade de avançar uma concepção de diversidade e de heterogeneidade que, em minha opinião, parece ser adequada para descrever a atitude de Kierkegaard face ao estilo, à produção autoral e à escrita enquanto modalidade privilegiada do pensar. Procurarei apresentar sumariamente essa concepção e seguidamente tratarei de desenvolver alguns aspectos complementares que me parecem apropriados à presente circunstância.

À primeira vista, dir-se-ia que a diversidade não exclui necessariamente a possibilidade de uma articulação com algum tipo de unidade. Por exemplo, parecerá possível pensar que a redução à unidade do "eu verdadeiro", que acabámos de observar no ensaio de Starobinski, é compatível com um certo grau de diversidade detectável nos diferentes pseudónimos ou nos diferentes tópicos que emergem nos diversos escritos do filósofo dinamarquês. A dificuldade, contudo, é que um tal grau de diversidade, como qualquer leitor de Kierkegaard facilmente constatará, não é propriamente um "certo" grau, ou seja, a diversidade não é uma "relativa" diversidade. Mesmo para aqueles leitores

\footnotetext{
7 As "inconsistências" - como lhes chama Genia Schönbaumsfeld (2002: 61-68) - de O Ponto de Vista Face à Minha Actividade de Autor foram estudadas em pormenor por Joakim Garff (2002: 71-96). A argumentação de Garff é parcialmente retomada e desenvolvida por Genia Schönbaumsfeld, op. cit.
}

Revista de Filosofia Moderna e Contemporânea

Brasília, vol 2, no 1, 2014. 
que acreditam que um texto como "Uma Primeira e Última Explicação" (no final do Postscriptum) ou um livro como O Ponto de Vista Face à Minha Actividade de Autor respondem completamente todas as questões respeitantes à multiplicidade de autores na produção kierkegaardiana, terá de parecer óbvio que, para lá do suposto efeito unificador de tais textos, permanece em aberto toda a complexidade de uma intrincada rede de relações, semi-relações e, por vezes, rejeições mútuas, pelo menos em três níveis específicos: ao nivel da produção autoral - i.e. entre os diferentes pseudónimos, mas também entre os pseudónimos e o autor Søren Kierkegaard -, ao nivel do estilo - uma vez que o estilo do pensar pode ser totalmente diferente de texto para texto, e, por vezes, de capítulo para capítulo, dentro do mesmo texto -, e ao nivel dos conteúdos - já que os conceitos, as categorias, os filosofemas ou muito simplesmente os tópicos escolhidos podem também variar espantosamente dentro de uma ampla gama de possibilidades.

Chamo diversidade precisamente a esta altamente complexa rede de diferenças. Insisto, contudo, que não se trata de um sistema de diferenças. É uma rede, mas alguns dos fios surgem deliberadamente quebrados, enquanto outros podem surgir interligados aqui e além, sem que contudo tais ligações permitam quaisquer generalizações. Outros fios simplesmente não conduzem a lado algum. E, no final, somos obrigados a chegar à conclusão de que não existe uma lógica global que possa permitir uma síntese discursiva do conjunto na sua totalidade. $\mathrm{O}$ carácter não-sistemático da dita rede é aqui da maior importância. Não há dúvida de que é possível detectar relações de complementaridade entre algumas obras ou alguns tópicos; mas, por outro lado, podemos detectar relações de rejeição mútua e relações de natureza totalmente indeterminada. Qual a lógica que governa, digamos, as relações entre Johannes de silentio e Constantin Constantius ou o A de Ou-ou? Qual a natureza comum de categorias como a de "repetição" e a de "angústia" (ou "ansiedade")? De um modo geral não é dada qualquer resposta a questões como estas, ou então a resposta é reduzida ao nível da mera biografia. E o nível da biografia parece-me ser precisamente a maneira mais simples de escapar por inteiro às dificuldades envolvidas na função constitutiva da diversidade na produção de Kierkegaard. Tais questões, na verdade, não têm uma resposta positiva, nem em termos filosóficos, nem em termos filológicos. As respostas terão de ser negativas, no sentido em que têm de descrever o nível exacto de diversidade que se joga em cada momento.

Digo que a função da diversidade é constitutiva, porque é possível reconhecer uma decisão do "autor dos autores" que vai neste sentido, por assim dizer, desde o princípio, e porque a obra de Kierkegaard não seria o que é se tal decisão não existisse. Essa decisão, contudo, não nos surge articulada de tal maneira que possa subsumir todas as possibilidades efectivamente postas em jogo nos diferentes escritos e inclusivamente nos Diários. De facto, é importante não esquecer o profundo sentido de experimentalismo envolvido na produção kierkegaardiana. Precisamente porque cada obra é, até certo ponto, uma experimentação, um experimento - $\mathrm{e}$, como se sabe, algumas obras estão explicitamente escritas como transcrições totais ou parciais de experimentos -, a decisão pela diversidade é estritamente incoativa, e não representa uma espécie de "unidade da diversidade" - que seria uma unidade negativa - capaz de eventualmente cobrir todas as possibilidades experimentais 
Singularidade e Universalidade nos processos de leitura de Kierkegaard

de cada obra ou de todo o conjunto das obras.

A diversidade e o experimentalismo estão profundamente interligados com um tópico abordado frequentemente por Kierkegaard, por exemplo, no Postscriptum e nos Diários: o tópico da infinitude, designadamente no par infinitude-finitude. Cito de uma passagem do Postscriptum não integrada na versão final:

\section{Entendido finitamente, $[\ldots]$ o esforço continuado, e perpetuamente continuado, em direcção a um objectivo, sem o alcançar, é rejeição, mas, entendido infinitamente, o esforço é precisamente a vida e é essencialmente a vida daquele que é composto do infinito e do finito. [...] [O] sujeito é um existente, consequentemente está em contradição, consequentemente está em processo de devir, consequentemente está, se estiver, no processo de esforçar-se. (Pap. VI B 35:24; JP5, 276) ${ }^{8}$}

Aquele que "é composto do infinito e do finito" - e, num certo sentido, todos nós somos, ou podemos vir a ser - está "no processo de esforçar-se". Este esforçar-se (Straben) é uma consequência do nosso processo de devir, o qual, por seu turno, é uma consequência do existir. A existência significa que estamos dentro de um processo e que esse processo é a cadeia de transformações sucessivas a que chamamos devir. Isto quer dizer que, se estivermos efectivamente no processo de esforço, toda a estabilidade de um sujeito assente na mesmidade, supostamente realizando continuamente as mesmas tarefas sem qualquer ganho de novidade nos seus pontos de vista, está completamente fora de causa. O campo em que se move aquele que se esforça é um terreno de diversidade, e é-o precisamente porque este sujeito não é exclusivamente composto de finitude, mas sim de "infinito e finito". Nesta perspectiva, a finitude é uma condição necessária da diversidade, mas não uma condição suficiente; sem a presença da infinitude no sujeito não haveria devir e, consequentemente, não haveria diversidade.

Podemos, pois, dizer que os três níveis de diversidade que identificámos atrás na obra de Kierkegaard - no plano da produção autoral, no plano do estilo do pensar e no plano dos conteúdos - são consequência da adopção de um ponto de vista que reúne finitude e infinitude na existência. $\mathrm{O}$ vasto conjunto de possibilidades a que temos vindo a chamar diversidade decorre inevitavelmente da presença da infinitude. Porém, a presença da infinitude abre igualmente o caminho para o experimentalismo. Na minha perspectiva, encaro os experimentos em pensamento de Kierkegaard como parte do esforço "entendido infinitamente" tal como é mencionado na passagem que citei acima. A infinitude não deverá ser encarada como uma espécie de linha recta, no tempo ou no espaço, meramente destituída de um fim ou de um princípio. Pelo contrário, nos usos que Kierkegaard faz da noção de infinitude, torna-se claro que esta última, porque exerce os seus poderes precisamente sobre a existência, é eminentemente multidireccional e as suas consequências são incontornavelmente dispersivas. Ora, esta dispersão é congenial com o esforçar-se, o

\footnotetext{
8 "Endeligen forstaaet er [...] den fortsatte og idelig fortsatte Stræben til et Maal uden at naae det, at forkaste, men uendeligt forstaaet er Stræben netop Livet og er væsentligen Dets Liv, der er dannet af det Uendelige og det Endelige. [...] Subjektet er existerende er altsaa i Modsigelsen er altsaa i Vorden er altsaa, hvis han er, i Stræben.” Este fragmento não consta da edição SKS.
} 
qual pode, num certo momento, ter um objectivo definido, mas que não pode ser completamente satisfeito por nenhum objectivo particular, ainda que esse objectivo seja a "verdade", a "salvação" ou a recuperação do "eu". Todos estes objectivos, do ponto de vista da existência, são objectivos parciais que não esgotam a multidão de possibilidades da infinitude e não põem fim ao processo de devir que despoleta o esforçar-se. O que se torna especialmente motivante neste ponto é precisamente o facto de o carácter dispersivo do esforçar-se implicar que o sujeito tem constantemente de ensaiar novas possibilidades - em novas direcções -, e esta multiplicidade de ensaios é exactamente aquilo a que podemos chamar uma colecção aberta de experimentos, designadamente, de experimentos em pensamento.

Após este esboço da nossa concepção de diversidade (e do tipo de experimentalismo que dela faz parte), tratemos agora de abordar o problema da heterogeneidade nos escritos de Kierkegaard ${ }^{9}$.

Chamo heterogeneidade a um tipo especial de diversidade que é observável em vários escritos do filósofo dinamarquês que, em vez de desenvolverem uma linha contínua de argumentação, apresentam um tipo de articulação interna em si mesmo composto por uma sequência de deslocações, de saltos e de descontinuidades. Exemplos privilegiados poderiam ser a natureza fragmentária da Parte I de Ou-ou, a sequência não-estruturada de Prefácios ou aquilo a que poderíamos chamar o efeitomigalhas das Migalhas Filosóficas. Mas, na verdade, o mesmo tipo de observações poder-se-ia aplicar a vários outros textos kierkegaardianos. No seguimento abordarei o caso das Migalhas Filosóficas.

Até certo ponto, as três questões que Climacus alinha no frontispício das Migalbas Filosóficas estabelecem a unidade temática do livro. Contudo, essa unidade é já composta por dois factores: o eterno e o histórico. Mas, em qualquer caso, cada uma das sete partes que constituem a obra (considero partes da obra não somente os capítulos numerados de I a V, mas também o Apêndice que se segue ao capítulo III e o Interlúdio entre os capítulos IV e V) tem, não apenas um tema especifico, mas também um conceito operativo interno próprio. Sobretudo com base nesta diferenciação operativa é possível reconhecer a dispersão direccional que caracteriza a heterogeneidade específica do livro no seu conjunto. Vejamos como funciona esta dispersão.

O cap. I centra-se tematicamente no tópico da diferença entre, por um lado, o modelo socrático-platónico da relação mestrediscípulo e, por outro lado, o modelo cristão da relação de "o deus" com o aprendiz. O conceito operativo específico deste capítulo é a categoria de "instante" (ou "momento"), a qual, na sua oposição em relação à noção de "ocasião", determina essencialmente o raciocínio que domina o capítulo. O cap. II lida com o tópico temático do amor "do deus" para com o homem. O respectivo conceito operativo situa-se agora no movimento de humilde "descida" que é crucial para que o amor do deus não se torne um "amor infeliz". O cap. III trata do tema do "paradoxo", e em

\footnotetext{
${ }^{9}$ Embora de maneira um pouco diferente, abordei este tópico no meu artigo "Kierkegaard's Writing and Infinitude. If We Are Finite, How Can We Relate or Refer to Infinitude?” (JUSTO, 2013a, pp. 180-184.) Partes desse artigo são aqui reproduzidas com modificações por vezes substanciais.
} 
Singularidade e Universalidade nos processos de leitura de Kierkegaard

particular da diferença entre o paradoxo socrático e o "paradoxo absoluto". O conceito operativo deste capítulo é o "salto" que se processa na passagem de um lado de um paradoxo para o outro. $\mathrm{O}$ Apêndice que se segue ao cap. III trata do tema do "escândalo face ao paradoxo", que é característico da relação infeliz que resulta de um encontro destituído da compreensão mútua entre o entendimento e o paradoxo. O conceito operativo do Apêndice é a categoria de passividade (o "sofrimento") que é afinal responsável pelo facto de ser o próprio paradoxo, e não o entendimento, a apreender o "escândalo". O tema proeminente no cap. IV é a relação entre o histórico e o eterno ou, numa outra formulação, toda a problemática relativa ao "começo da eternidade". O conceito operativo aqui dominante é a "fé". Após o cap. IV surge o Interlúdio, que tem uma estrutura temática complexa: o Interlúdio debruça-se sobre uma sequência de diferentes aspectos do tempo, partindo do tópico da liberdade, passando depois aos tópicos do histórico, do passado e da apreensão do passado, para regressar finalmente ao problema da liberdade, designadamente na sua relação fundamental com a fé. O conceito operativo do Interlúdio é o "vir à existência" (Tilblivelse) que se torna central para o tratamento dos núcleos temáticos desta secção. Por último, o cap. V trata o tema do "discípulo de segunda mão", em particular as diferenças entre a primeira e a última gerações de discípulos de segunda mão. Quanto ao conceito operativo deste último capítulo, pode dizer-se que é de ordem negativa: esse papel operativo é desempenhado pela categoria de tempo, mas exactamente no sentido em que aqui o tempo se extingue na sua eficácia, sendo o objectivo o de subverter a ideia de uma diferença fundamental entre a primeira e a última gerações de discípulos de segunda mão, e mesmo entre o discípulo contemporâneo e o discípulo de segunda mão.

Imaginemos por um momento que, do ponto de vista temático, o leitor encontra uma possibilidade de reconstruir uma linha sequencial desde o início do livro até ao final do último capítulo. Uma tal possibilidade, contudo, implica que não preste grande atenção às deslocações temáticas claramente observáveis de capítulo para capítulo. E exige também que o leitor adopte um ponto de vista global que, até certo ponto, tem de localizar-se acima da obra no seu conjunto, de modo a executar um trabalho de reconstrução que obviamente se expõe aos perigos da híperinterpretação. Contudo, o aspecto que mais me importa é aquele que tem a ver com a sequência daquilo a que chamei conceitos operativos. É notável o modo de articulação profundamente heterogéneo de tais conceitos: por exemplo, a categoria de "instante" não oferece nenhum tipo de continuidade em face das restantes categorias, em especial no que toca à categoria de "descida" humilde; o "instante" e a "descida" humilde, se os compararmos com a categoria de "salto", operam em sentidos muito diversos; a passividade não surge em nenhum tipo de conexão com os conceitos operativos que ocorrem antes ou depois; a natureza da categoria de "fé" é completamente diversa da natureza das categorias de "instante", "salto" ou "vir à existência"; o "vir à existência" merece da parte de Climacus uma exposição pormenorizada que não tem paralelo nas restantes categorias; e, finalmente, a categoria de tempo negativo do último capítulo apresenta-se em nítida oposição à problemática do tempo, tal 
como ela ocorre em ocasiões diversas ao longo da obra.

Tudo isto nos leva a concluir que esta característica, que a meu ver merece o nome de heterogeneidade, não funciona num nível superficial, no qual o leitor pudesse encontrar meros exemplos de descontinuidade até certo ponto negligenciáveis. Antes pelo contrário, ela opera num nível profundo de articulação interna dentro de certas obras. Uma tal heterogeneidade impede-nos completamente de usar uma concepção de unidade ao nível de cada uma das obras em que ela se manifesta. Mas, uma vez que a heterogeneidade é um problema que diz respeito àquilo a que chamei acima a multiplicidade de estilos kierkegaardianos do pensar, então ela contribui decisivamente para que evitemos estabelecer qualquer tipo de teoria unificada dos modos de pensamento no nosso autor. A diversidade e a heterogeneidade chocam-se decididamente contra qualquer tentativa de redução à unidade.

\section{Singularidade vs. diversidade e heterogeneidade}

Introduzo agora a ideia de singularidade como uma possibilidade de ultrapassar o efeito negativo de instâncias como a diversidade e a heterogeneidade. A questão que pretendo tratar pode ser inicialmente formulada nos seguintes termos: como poderemos nós, em face da produção kierkegaardiana, estabelecer um ponto de vista que, sem cair nas armadilhas de uma falsa unidade, possa ao mesmo tempo ser suficientemente positivo para extrair das observações acerca da diversidade e da heterogeneidade uma análise discursiva das obras - e da obra - que contenha um elevado grau de produtividade hermenêutica? Por outras palavras: como pode o leitor de Kierkegaard construir a sua própria subjectividade de leitor em face de uma obra que incontornavelmente se afigura heterogénea e dispersiva? E uso deliberadamente esta expressão - "construir a sua própria subjectividade de leitor" -, porque do ponto de vista em que me coloco Kierkegaard é um daqueles autores que não podem ser lidos sem que a "existência" do leitor seja posta em jogo na leitura e sem que isso implique precisamente uma transformação da subjectividade, ou seja, um abalar de convicções prévias que, por seu turno, desencadeia uma construção de uma outra subjectividade - se não integralmente, pelo menos de modo parcelar. Voltarei a este tópico no final desta conferência.

\section{Acerca da singularidade e da universalidade da experiência}

Começarei por expor muito abreviadamente os aspectos principais de uma teoria da singularidade que, como já tenho tido oportunidade de mostrar em anteriores ocasiões, me parece necessária para a abordagem quer do problema da experiência estética, quer dos factos hermenêuticos. $O$ primeiro passo será o de distinguir entre singularidade e particularidade, por um lado, e entre singularidade e generalidade, por outro. $\mathrm{O}$ segundo passo consistirá em estabelecer uma relação dinâmica entre a singularidade e um certo entendimento específico da universalidade. $\mathrm{Na}$ secção seguinte desta conferência procurarei verificar a aplicabilidade desta teorização na leitura de Kierkegaard. 
Singularidade e Universalidade nos processos de leitura de Kierkegaard

O uso linguístico comum não distingue com clareza a singularidade e a particularidade. Chamo particulares àquelas experiências que são eminentemente privadas e que não comunicam com outras experiências, nem sequer encontram caminho - enquanto particulares - no sentido de uma efectiva verbalização. Pelo contrário, os singulares da experiência podem ser caracterizados como processos em que o direccionamento anterior do nosso pensar (ou o nosso anterior direccionamento perceptivo) é subitamente interrompido por algum tipo de facto que, devido à sua exclusividade, começa por constituir um obstáculo, e depois, mais tarde ou mais cedo, gera uma mudança de direcção na trajectória anterior do pensar, proporcionando-nos uma nova visão capaz de iluminar não só a experiência em causa como várias outras experiências. A singularidade da experiência é porventura a primeira e mais elementar forma de produrir sentido no seio das nossas actividades, designadamente nas nossas actividades criativas, como são o pensar e a interpretação. Os singulares não são factos isolados precisamente porque comunicam com outras experiências e contaminam-nas com o seu efeito de produção de sentido.

Os singulares podem apresentar uma relação fundamental com a linguagem, uma vez que a trajectória prévia do pensar e o processo de redireccionamento - tanto quanto os efeitos deste redireccionamento - podem ser eminentemente verbais. Mas a função da linguagem que pode detectar-se a este nível não deve ser confundida com aquela que se processa na generalização. $\mathrm{O}$ papel da linguagem na nossa experiência da generalidade é fundamentalmente indutivo, e não pode comparar-se com o grau de novidade - e sobretudo de certeza - que anda ligado aos singulares. Se falo de certeza neste contexto, não é num sentido eminentemente lógico, mas sim como maneira de me referir à eficiência dos singulares quanto ao respectivo efeito sobre outras experiências.

Falando agora das relações entre singulares e universais, a primeira coisa a sublinhar é que também aqui não me refiro aos universais numa perspectiva estritamente lógica. Penso que há boas razões para aceitar, pelo menos parcialmente, o velho argumento nominalista, segundo o qual os universais são nomes, mas considero-os como factos da experiência, tal como os singulares são factos da experiência. Subsiste, contudo, uma importante diferença entre os singulares e os universais. Os singulares, como disse, têm o efeito de iluminar intensamente outros factos da experiência, mas não têm um efeito de totalidade ou de absoluto. Os universais, pelo contrário, quando os alcançamos, oferecem-nos um grau de certeza muito mais amplo. Tendem a cobrir todo o conjunto da nossa experiência - ou todo um território da nossa experiência - e a fornecer-nos uma avaliação absoluta das nossas acções passadas e futuras. Os universais são consequência de um salto que nos transporta de um domínio de experiências dispersas para uma perspectiva totalizante que nos envolve a nós mesmos e o mundo que nos rodeia.

É possível distinguir entre universais irracionais e universais que, pelo menos até certo ponto, se apresentam como um efeito da racionalidade. Aqueles universais que são obtidos por um salto directo efectuado a partir das particularidades da experiência são fundamentalmente irracionais; é o caso de universais derivados a partir de experiências místicas ou com 
base em algum tipo de conversão não fundamentada. Contudo, defendo que há universais que se obtêm através de um salto de natureza diferente; um salto em que é possível determinar uma sequência prévia de pensamentos (ou de percepções) que num certo momento dá subitamente lugar a um efeito de universalidade. Nestes casos, o processo anterior à descontinuidade do salto é susceptível de ser compreendido no seu desenvolvimento e, nesta perspectiva, podemos descrever a sua racionalidade parcial. Do ponto de vista que aqui adopto, é precisamente isto que acontece quando a singularidade $\mathrm{da}$ experiência expande a sua eficácia e é subitamente transformada num universal que deixa de se aplicar apenas a um certo conjunto de experiências e passa a aplicarse à totalidade da nossa experiência, pelo menos dentro de um certo campo de acção.

Uma última palavra acerca dos universais antes de passarmos ao caso de Kierkegaard: é importante sublinhar que nesta perspectiva os universais são vistos como sendo históricos e provisórios. Eles são produto nosso, num determinado momento no tempo, e consequentemente não podem reclamar nenhum tipo de eternidade. Neste sentido, um universal pode durar alguns segundos ou muitos anos, mas poderá sempre ser substituído por um outro universal que subitamente se adequa melhor às nossas experiências e, porventura, às nossas novas crenças. Por outro lado, os universais não têm necessariamente de ser vistos como mutuamente exclusivos; diferentes universais podem coexistir em diferentes áreas ou níveis da nossa experiência, ou até dentro de um mesmo nível.

\section{Singularidade e universalidade em Kierkegaard}

Os diferentes níveis de diversidade que observámos atrás na obra de Kierkegaard, e o tipo de heterogeneidade que procurámos caracterizar deixam-nos - ou deixam o leitor - numa situação que à primeira vista surge como extremamente improdutiva. $\mathrm{O}$ leitor perguntará a si próprio o que fazer com a descoberta dessa diversidade e dessa heterogeneidade, e como avançar na compreensão das obras após tais descobertas. Estaremos condenados a um discurso meramente fragmentário acerca de um conjunto de obras que é profundamente dispersivo - ou disseminante -, e que, para além disso, é em grande parte constituído por textos de natureza fragmentária?

Não creio que seja precisamente esta a situação com que nos defrontamos neste instante. $\mathrm{Na}$ perspectiva em que me coloco, entre a redução à unidade e essa situação aparentemente improdutiva existe pelo menos uma outra possibilidade, e a possibilidade de que vos falo está profundamente ligada ao reconhecimento de um nível específico de singularidade susceptível de ser encontrado na obra de Kierkegaard. Trata-se da singularidade daquilo a que chamarei "problemas", adoptando aqui o termo que Johannes de silentio usa em Temor e Tremor, e adoptando igualmente (como na verdade de silentio também faz) as conotações de uma parte da etimologia grega da palavra. No grego antigo, um problema era, antes de mais, uma "protuberância", por exemplo um "cabo" ou um "promontório" na costa; depois a palavra significou "aquilo que se nos apresenta", e posteriormente "obstáculo", de onde deriva o significado corrente de "problema". No sentido de obstáculo, um problema tem muito em comum com

Revista de Filosofia Moderna e Contemporânea

Brasília, vol 2, no 1, 2014. 
Singularidade e Universalidade nos processos de leitura de Kierkegaard

aquilo que caracterizei como o fulcro de uma singularidade.

Do meu ponto de vista, no conjunto da obra kierkegaardiana, são detectáveis problemas específicos - alguns deles emergindo como categorias ou filosofemas, outros nem tanto -, os quais, por um lado, funcionam como obstáculos ao nosso entendimento progressivo de uma certa obra ou grupo de obras, e, por outro lado, operam exactamente como singularidades. $\mathrm{E}$ é assim, porque, mais tarde ou mais cedo, tais problemas obrigam a uma mudança de rumo do nosso fluxo prévio de entendimento, obrigando-nos a adoptar um direccionamento diferente na nossa leitura e a descobrir um sentido novo, previamente insuspeitado, para uma dada passagem, um capítulo, um grupo de capítulos, ou todo um livro. Para além disso, estes problemas - que procuro caracterizar como singulares da nossa experiência hermenêutica de um texto ou grupo de textos - apresentam ainda uma outra característica própria da singularidade: é que depois de nos indicarem uma nova direcção de pensamento, são capazes de entrar numa relação hermenêutica com outros problemas, ou mesmo com secções não problemáticas do mesmo texto ou de outros textos, efectuando assim um trabalho de reinterpretação destes outros momentos textuais. E, por último, é também possível, embora mais raramente, que tais problemas singulares alcancem $\mathrm{o}$ nível em que subitamente deixam de ser meras singularidades e se transformam em autênticos universais, no sentido que indiquei acima.

No seguimento, tratarei de exemplificar o que acabo de formular em termos gerais e abstractos. Imaginemos que um leitor está pela primeira vez confrontado com $\mathrm{O}$ primeiro dos Três Discursos Edificantes de 1843: "A caridade cobrirá a multidão de pecados" ou "O amor cobre a multidão dos pecados" 10 . Num certo momento da sua leitura o leitor chega ao tópico da "multiplicidade do pecado" ("Syndens Mangfoldighed", SKS 5, 70), que aliás, em boa verdade, já está no título do Discurso, uma vez que aquilo que traduzimos por "multidão" (ou "multitude" na tradução inglesa) se exprime em dinamarquês pelo mesmo termo: Mangfoldighed. A ideia de uma "multiplicidade" constitui problema, já que pode ao mesmo tempo ser lida como uma entidade filosófica - que requer um mecanismo capaz de efectuar a respectiva redução - e como uma expressão que Kierkegaard recolhe das Escrituras para falar sobre as características do pecado, designadamente sobre a sua tremenda capacidade de disseminação, que só pode ser vencida pelo amor. Neste último sentido, a "multiplicidade" não é uma entidade filosófica, mas sim uma entidade tipicamente teológica. Esta concomitância constitui um aspecto inicial do problema. Mas há mais: Kierkegaard diz também que "a palavra apostólica [...], para ser compreendida, tem de ser tomada

10 Como é sabido, a expressão que dá título a esse discurso edificante é extraída da primeira epístola de Pedro, 4:8. A primeira tradução que indico é a de João Ferreira d'Almeida, a segunda é a da chamada Nova Bíblia dos Capuchinhos.

Revista de Filosofia Moderna e Contemporânea

Brasília, vol 2, no 1, 2014. 
à letra" (SKS 5, 69) $)^{11}$. Isto significa designadamente que o termo "cobrir" (dinamarquês skjule, que pode também significar encobrir ou esconder), nas palavras do apóstolo, não só não significa de modo algum a possibilidade de uma redução filosófica, como nos obriga a aceitar que, do ponto de vista teológico, o "amor" não procede simplesmente a um apagamento do pecado. O amor é de facto poderoso, mas o seu poder não extingue simplesmente o pecado e a respectiva "multiplicidade". Este é, pois, o segundo aspecto do problema.

Uma vez colocado perante o problema, o leitor tem de procurar algum elemento textual capaz de desviar a sua linha de pensamento e iluminar a situação. Parece claro que tentar simplesmente penetrar o problema sem a ajuda de outros factos textuais não conduzirá a solução alguma, uma vez que estamos aqui a lidar com um verdadeiro obstáculo. Supondo que existe uma solução, ela terá de ser buscada em algum outro lugar.

Suponhamos agora que o leitor se detém numa passagem do mesmo texto que, apesar de em parte tratar de um tópico diferente, pode ter uma súbita eficácia relativamente ao problema que se lhe colocou:

Quando no coração mora a irascibilidade, aí o individuo é rápido a descobrir a multiplicidade do pecado, ai entende magnificamente um meio- discurso, capta apressadamente à distância a palavra que mal chega a ser pronunciada. Quando no coração mora o amor, aí o individuo entende devagar, e não ouve de todo uma palavra apressada, e não entende a respectiva repetição, porque the dá um bom lugar e uma boa significação, não entende o longo discurso da cólera ou do sarcasmo, porque aguarda ainda por uma palavra mais que haja de dar significação ao discurso. (SKS 5, 70)12

O Discurso introduz aqui um duplo movimento hermenêutico: o da irascibilidade, da velocidade e do pecado, por um lado, e o do amor e da lentidão, por outro lado. A passagem citada trata do tópico do "entender" e da interpretação, e estabelece a diferença entre os modos de entender daquele que vive na irascibilidade e daquele que, vivendo no amor, vive também num ritmo lento. A diferenciação dos ritmos é obviamente de grande importância para a diferenciação dos dois tipos de entendimento. A oposição entre o tempo rápido do pecado e o tempo lento do amor permitenos compreender que um entendimento apressado destrói completamente o nível de fragmentação necessário para o verdadeiro processo hermenêutico, e que o entendimento lento abre o caminho para um tipo de compreensão que é iluminador precisamente porque é capaz de aguardar por "uma palavra mais". No entanto, o que me parece ser crucial é o facto de que, a partir do momento em que conseguimos circunscrever a diferenciação dos ritmos, podemos subitamente encarar de uma maneira inteiramente nova o problema da

\footnotetext{
11 "Vi ville lade vor Sjæl hvile i det apostoliske Ord, der ikke er en svigefuld poetisk Vending, ikke et dristigt Udbrud, men en trofast Tanke, et fuldgyldigt Vidnesbyrd, der for at forstaaes maa tages efter Ordet."

12 "Naar der i Hjertet boer Iilsindethed, da er Mennesket snart til at opdage Syndens Mangfoldighed, da forstaaer han herligt en halv Tale, fatter hasteligen langtfra Ordet, som neppe er udtalt. Naar der i Hjertet boer Kjerlighed, da forstaaer et Menneske langsomt, og hører slet ikke et hastigt Ord, og forstaaer ikke dets Gjentagelse, fordi han giver det et godt Sted, og en god Mening, forstaaer ikke Vredens eller Spottens lange Tale, fordi han venter endnu eet Ord, der skal give Talen Mening."
}

Revista de Filosofia Moderna e Contemporânea

Brasília, vol 2, no 1, 2014. 
Singularidade e Universalidade nos processos de leitura de Kierkegaard

multiplicidade, por um lado, e do amor na sua função de "cobrir" uma "multidão de pecados", por outro. A multiplicidade - ou multiplicação ou disseminação - do pecado está sempre dependente da rapidez do tempo, e a eficácia do amor não seria possível se $\mathrm{o}$ amor não escolhesse $\mathrm{o}$ terreno de um tempo distendido, um tempo lento. Este facto significa duas coisas: em primeiro lugar, do ponto de vista dos conceitos filosóficos, a multiplicidade deixa de poder ser vista como um nível da experiência que requer um processo de redução; em vez disso, a modificação requerida passa agora a ser vista ao nível dos ritmos e da sua diferenciação; em segundo lugar, do ponto de vista teológico, a disseminação deixa de ser uma característica primeira do pecado e torna-se totalmente dependente $\mathrm{da}$ irascibilidade, que é como quem diz, da rapidez. Quanto à função do amor, naquela sua acção de "cobrir" os pecados que, como vimos, não os elimina simplesmente, torna-se agora parte integrante de uma oscilação totalmente dependente da escolha de um ou do outro ritmo.

A minha conclusão, neste ponto, é que o obstáculo que o leitor encontrou o conduziu agora a uma inflexão no decurso inicial do seu pensamento, e que estamos portanto na presença de um efeito de singularidade. $\mathrm{O}$ próximo passo será o de mostrar as conexões que um tal efeito de singularidade pode estabelecer com outros tópicos, conceitos ou categorias dentro da obra de Kierkegaard. Fá-lo-ei de maneira abreviada.

Escolho de entre muitos outros exemplos possíveis a categoria de repetição, no livro de Constantius. A ideia que defendo é a de que a singularidade do tópico da multiplicidade, quando relida à luz da diferenciação dos ritmos, ilumina a categoria de repetição na medida em que permite compreender que a questão da repetição é uma questão hermenêutica que depende de um ritmo específico, designadamente o ritmo lento do tempo distendido. A repetição - tal com a recordação entre os gregos - não é apenas uma categoria importante para estabelecer uma certa compreensão do conhecimento; a repetição tem também - e, a meu ver, sobretudo - um interesse hermenêutico, já que regula a nossa compreensão dos factos e a produção de sentido em diferentes áreas da nossa experiência, ou da "vida", como diz Constantius. E a eficácia hermenêutica da repetição seria impossível se não lhe fosse dado um tempo dilatado para poder acontecer, e para acontecer precisamente de um modo repetido. Uma repetição na irascibilidade, ou num ritmo acelerado, produziria exactamente o mesmo que já havia sido produzido antes, ou seja, seria incapaz de dar lugar a qualquer novidade de significação ou de sentido. A repetição, para poder significar algum enriquecimento da nossa existência, precisa de se exercer num tempo dilatado, semelhante àquele em que age o amor. Para além disso, a repetição trata também da questão da multiplicidade; mas, uma vez mais, sob a luz daquela específica singularidade que examinámos acima, podemos igualmente compreender que ela não submete a multiplicidade a um simples processo de redução, tal como também não se limita a aniquilá-la. A repetição, graças à sua acção hermenêutica, abre a possibilidade de novas maneiras de ver e de novas significações que emergem em cada momento como alternativas possíveis - ou seja, que não são de uma imperatividade exclusiva - para multiplicidades específicas. 
Por fim, e também de maneira abreviada, procurarei mostrar que também o salto entre o singular e o universal a que aludi atrás é susceptível de ser pensado no âmbito do exemplo de que tenho vindo a falar.

A singularidade que começa com o problema da multiplicidade e permite ao leitor transformar o obstáculo numa perspectiva dominada pela diferenciação dos tempos pode, de facto, entrar num processo de descontinuidade e subitamente iluminar de um modo completamente novo toda uma série de tópicos ou categorias directamente relacionados com o tempo. Um bom exemplo é o das diferentes categorias do tempo numa obra como Migalhas Filosóficas. Essas categorias são (pelo menos) as seguintes: o histórico, o eterno, o passado, o instante, o começo do tempo e o vir à existência. Se o leitor chegou àquele momento em que é capaz de aplicar o efeito da diferenciação dos ritmos a uma categoria como a de repetição, torna-se bastante possível que, mais cedo ou mais tarde, se estabeleça uma relação de outro tipo efectivando um salto do plano da singularidade para o da universalidade, ou seja, da eficiência mais ou menos localizada de um singular para uma perspectiva global acerca das categorias do tempo, gerando assim a imagem de um conjunto totalizado que assume os traços característicos de um ponto de vista absoluto. $\mathrm{Na}$ verdade, quando avançamos do mencionado Discurso Edificante de 1843 para as Migalhas Filosóficas, a distinção dos ritmos tende a expandir imensamente o seu efeito hermenêutico, surgindo - naquele momento que tenho vindo a designar como um "salto" - como sendo capaz de clarificar um vasto conjunto de ocorrências de categorias do tempo. Para dar apenas um exemplo, tal é o que sucede com a categoria de "instante", quando a vemos ao mesmo tempo como uma modalidade extrema da velocidade (envolvendo, sem dúvida, uma descontinuidade constitutiva) e como uma modalidade extrema da lentidão (envolvendo também uma descontinuidade do mesmo tipo). Porém, uma vez que sabemos que a lentidão vence a pressa - a velocidade e a irascibilidade que lhe está associada - (sem, contudo, a aniquilar), sabemos também que o ponto de vista da lentidão é aquele que pode clarificar o que se joga na categoria de instante. O instante é, no tempo, um ponto sem tempo, que só pode ser captado exactamente na medida em que o sujeito da experiência se encontre do lado do tempo lento e distendido, sem o qual essa experiência iluminante do instante (que é, sem dúvida, uma experiência de descontinuidade) não pode ter lugar, pela simples razão de que não há tempo para que ela aconteça.

Insisto, porém, que o referido salto de uma singularidade para um efeito de universalidade não se confunde com uma mera redução à unidade. Uma redução à unidade apresenta-se como um processo de racionalização que comporta uma instância de necessária continuidade. Pelo contrário, a passagem de um singular da experiência hermenêutica para um efeito hermenêutico de universalidade envolve uma descontinuidade constitutiva e não é de facto possível sem a intervenção daquilo a que teremos de chamar uma crença. $\mathrm{O}$ salto de que falámos é correlativo de uma intervenção da crença. Sucede somente, como referi mais atrás, que estamos a lidar aqui com um tipo de crença que não emerge do âmbito da particularidade da experiência, e que, neste sentido, manifesta uma racionalidade parcial, já que é possível, 
Singularidade e Universalidade nos processos de leitura de Kierkegaard

no plano da singularidade, descrever o trajecto específico que conduz até ao salto.

Para usar aqui uma conhecida expressão de Marcel Proust, no último volume de Em Busca do Tempo Perdido, Kierkegaard é, sem dúvida, um daqueles autores que obrigam o leitor a ser "o próprio leitor de si mesmo" (PROUST, 1987-1989, IV: 489). Este "leitor de si mesmo", como faz notar muito apropriadamente num trabalho recente o filósofo francês Pierre Macherey (2013: 33), tem duas vertentes, a do genitivo subjectivo e a do genitivo objectivo. Por um lado, o leitor de si mesmo é um leitor por conta própria, obrigado a investir o que sabe - e porventura aquilo que ainda não sabe - na construção de possibilidades de leitura. Mas, por outro lado, e ao mesmo tempo, essa construção é também, por parte do leitor, uma outra construção que recai sobre a sua própria subjectividade. As duas vertentes não são independentes uma da outra. A construção de possibilidades de leitura é simultaneamente a construção da subjectividade do leitor, construção de instâncias sucessivas de subjectividade que a todo o momento vão reconfigurando uma totalidade - obviamente uma totalidade aberta - da subjectividade. Kierkegaard, na verdade, não nos deixa outra alternativa. A complexidade e a disseminação da sua escrita, por um lado, e o imperativo radical contido na sua obra no sentido de nos colocarmos do lado da existência real, e não mais do lado de uma sistemática abstracta, obrigam-nos incontornavelmente a procurar os nódulos de singularidade e os planos de universalidade (ainda que provisórios) capazes de fornecerem os instrumentos e os materiais da construção não só da nossa interioridade, mas também da nossa vivência comunitária e do nosso relacionamento pessoal com tudo o que nos rodeia, ou seja, numa só palavra, da construção diferencial da subjectividade de cada um de nós, no sentido mais amplo do termo. Kierkegaard convida-nos a viver este imenso desafio da subjectividade, mas em simultâneo convida-nos igualmente a viver permanentemente em desafio, ou seja, no desafio que ele soube colocar à própria mutabilidade dinâmica da subjectividade.

\section{Referências bibliográficas}

GARFF, J. "The Eyes of Argus - The point of view and points of view with respect to Kierkegaard's 'Activity as an Author"'. In: Conway, D. (Ed.), Soren Kierkegaard - Critical Assessments of Leading Philosophers, Volume I. London: Routledge, 2002, pp. 71-96.

JASPERS, K. "Kierkegaard hoy". Trad. A. Sánchez Pascual. In: Sartre, J. P., Heidegger, M., Jaspers, K. et al., Kierkegaard vivo. Madrid: Alianza, 1970, pp. 63-72.

JUSTO, J. M. "Kierkegaard's Writing and Infinitude. If We Are Finite, How Can We Relate or Refer to Infinitude?”. In: Justo, J. M., Sousa, E., M., Rosfort, R. (Eds.), Kierkegaard and the Challenges of Infinitude. Philosophy and Literature in Dialogue. Lisbon: CFUL, 2013, pp. 173-184.

JUSTO, J. M. "Kierkegaard: Unity or Singularity". Rivista di Filosofia NeoScolastica, Milão, 3-4 (2013), pp. 897-912, 2013b. 
José Miranda Justo

KIERKEGAARD, S. Soren Kierkegaards Papirer. Org. P. A. Heiberg, V. Kuhr e E. Torsting. København: 1909-1948 (Abrev.: Pap. seguido da numeração do fragmento atribuída nessa edição.).

KIERKEGAARD, S. Soren Kierkegaards Skrifter. Org. Niels Jørgen Cappelørn, Joakim Garff et. al. København: Søren Kierkegaard Forskningscenteret, Gads Forlag, 1997-2013. (Abrev.: SKS, seguido do número do volume em romanos e da página em árabes.)

MACHEREY, P. Proust. Entre littérature et philosophie. Paris: Éditions Amsterdam, 2013.

PROUST, M. Le temps retrouvé: À la recherche $d u$ temps perdu, tome IV. Paris: Bibliothèque de la Pléiade, Gallimard, 1987-1989.

SCHÖNBAUMSFELD, G. A Confusion of the Spheres. Kierkegaard and Wittgenstein on Philosophy and Religion. Oxford, New York: Oxford University Press, 2007.

STAROBINSKI, J. L'Encre de la mélancolie. Paris: Seuil, 2012.

Revista de Filosofia Moderna e Contemporânea Brasília, vol 2, n 1, 2014. 